\title{
Differentiation of Skull Base Chordomas from Chondrosarcomas by Diffusion-Weighted MRI
}

W e read with great interest the recent article entitled "Diffusion-Weighted MRI: Distinction of Skull Base Chordoma from Chondrosarcoma" by Yeom et al. ${ }^{1}$ The authors showed, with a sample of 19 patients, that skull base chondrosarcomas could be differentiated from chordomas and from atypical chordomas by ADC values on diffusion-weighted MR imaging. This result represents a significant advance, because there are no other imaging approaches to reliably distinguish these central skull base tumors. We have now replicated these findings with a sample of 14 chordoma and 10 chondrosarcoma cases from our own institution. Similar to Yeom et al, we found that chondrosarcomas demonstrate substantially larger average ADC values compared with chordomas and that this difference is highly significant (chondrosarcoma median ADC: $214 \times 10^{-5} \mathrm{~mm}^{2} / \mathrm{s} ; 25$ th percentile: $176 \times 10^{-5} \mathrm{~mm}^{2} / \mathrm{s} ; 75$ th percentile: $229 \times 10^{-5} \mathrm{~mm}^{2} / \mathrm{s}$; chordoma median ADC: $135 \times 10^{-5} \mathrm{~mm}^{2} / \mathrm{s} ; 25$ th percentile: $116 \times$ $10^{-5} \mathrm{~mm}^{2} / \mathrm{s}$; 75 th percentile: $144 \times 10^{-5} \mathrm{~mm}^{2} / \mathrm{s} ; P<.001$, Mann-Whitney $U$ test). Chordomas have a significantly worse

http://dx.doi.org/10.3174/ajnr.A3723 prognosis than chondrosarcomas, with 5-year progression-free survival estimated at $80 \%$ for chondrosarcomas but only $40 \%$ for chordomas. ${ }^{2}$ Thus, distinguishing these 2 entities has important implications for treatment planning and patient counseling. Further investigation of diffusion-weighted MR imaging of skull base tumors should be pursued, because it is likely to identify additional diagnostic and prognostic features that will impact clinical and surgical management of these lesions.

\section{REFERENCES}

1. Yeom KW, Lober RM, Mobley BC, et al. Diffusion-weighted MRI: distinction of skull base chordoma from chondrosarcoma. AJNR Am J Neuroradiol 2013;34:1056-61

2. Cho YH, Kim JH, Khang SK, et al. Chordomas and chondrosarcomas of the skull base: comparative analysis of clinical results in $\mathbf{3 0}$ patients. Neurosurg Rev 2008;31:35-43, discussion 43

B.S. Freeze

Department of Radiology and Biomedical Imaging Medical Scientist Training Program

C.M. Glastonbury

Department of Radiology and Biomedical Imaging University of California, San Francisco San Francisco, California 